\title{
INTERKONEKSI IPv6 DENGAN IPv4 MENGGUNAKAN DSTM (DUAL STACK TRANSITION MECHANISM)
}

\author{
Dody Setiawan ${ }^{1}$, R. Rumani M. ${ }^{2}$, Nyoman Bogi A. K. ${ }^{3}$ \\ Jurusan Teknik Elektro - Sekolah Tinggi Teknologi Telkom, Bandung \\ ${ }^{2}$ rrm@stttelkom.ac.id, ${ }^{3}$ nbg@ @stttelkom.ac.id
}

\begin{abstract}
Abstrak
Dual Stack Transition Mechanism (DSTM) menyediakan metoda yang memungkinkan host IPv4 dapat berkomunikasi dengan host IPv6 dengan menggunakan IPv4-over-IPv6 Tunnel. Penelitian ini akan mempelajari mekanisme kerja, implementasi DSTM, serta pengujian kinerjanya. Hasil analisis menunjukkan peningkatan waktu tempuh paket pada proses pengiriman data melalui jaringan IPv6 ke IPv4 dan sebaliknya akibat proses enkapsulasi ataupun dekapsulasi datagram IP.
\end{abstract}

Kata kunci: IPv4, IPv6, DSTM, Tunneling, IPv6 Tunnel Broker, Delay FTP, ping dan Iperf

Abstract

Dual Stack Transition Mechanism (DSTM) provide a method that allow IPv4 host to communicate with IPv6 host using IPv4-over-IPv6 tunneling. This paper will show how DSTM works, the implementation, and the system performance. Analysis result show an increasing packet time trip when a packet is transfered from IPv6 network to IPv4 and vice versa because of encapsulation and decapsulation process of IP datagram.

Keywords: IPv4, IPv6, DSTM, Tunneling, IPv6 Tunnel Broker, Delay FTP, ping and Iperf

\section{Pendahuluan}

Jaringan Internet mengalami pertumbuhan yang sangat pesat. Penggunaan pengalamatan IPv4 di internet saat ini sudah tidak memadai dalam menghadapi banyaknya permintaan akan alamat baru. Pengalamatan menggunakan IPv6 menawarkan jumlah alamat yang jauh lebih besar.

Untuk dapat menggunakan IPv6, terdapat permasalahan baru, yaitu cara yang tepat untuk melakukan transisi dari IPv4 ke IPv6. Salah satu mekanisme transisi adalah melalui DSTM (Dual Stack Mechanism Transition). Dengan DSTM, host yang berada pada jaringan IPv6 dapat terkoneksi dengan host pada jaringan IPv4, dan juga sebaliknya.

Penelitian ini bertujuan mengimplementasikan dan menganalisis sistem DSTM pada jaringan IPv6 sehingga dapat saling terkoneksi dengan jaringan IPv4, dan saling memberikan layanan yang terdapat pada masing-masing jaringan.

\section{IPv4 dan IPv6: Perbedaan dan Transisinya}

\subsection{Perbedaan IPv6 dengan IPv4}

Terdapat sejumlah perbedaan mendasar pada IPv4 dan IPv6, antara lain dalam hal: struktur pengalamatan, struktur paket, dan metoda fragmentasi paket, seperti diperlihatkan pada Gambar 1 dan Gambar 2. IPv4 memiliki struktur pengalamatan 32 bit, sedangkan IPv6 menggunakan 128 bit, sehingga jumlah kombinasi alamat IPv6 jauh lebih besar ketimbang IPv4.

\begin{tabular}{|c|c|c|c|}
\hline Ver & Hlen & TOS & Total length \\
\hline \multicolumn{2}{|c|}{ Identifications } & Flags & Flag offset \\
\hline TTL & Protocol & Header Checksum \\
\hline \multicolumn{3}{|c|}{ Source address } \\
\hline \multicolumn{3}{|c|}{ Destinations address } \\
\hline \multicolumn{3}{|c|}{ Options and padding } \\
\hline
\end{tabular}

Gambar 1. Struktur Paket IPv4

\begin{tabular}{|c|c|c|}
\hline Ver & Traffic class & Flow Label \\
\hline Payload length & Next header & Hop limit \\
\hline \multicolumn{3}{|c|}{ Source address } \\
\hline \multicolumn{3}{|c|}{ Destinations address } \\
\hline
\end{tabular}

Gambar 2. Struktur Paket IPv6

Karena ukuran muatan paket bertambah, maka metoda fragmentasi akan mengalami perubahan pula. Fragmentasi merupakan sebuah metoda untuk melewatkan sebuah muatan berukuran melebihi MTU (Message Transfer Unit) dengan cara memecah paket tersebut menjadi beberapa bagian paket. Ukuran MTU ditentukan oleh media yang digunakan, sebagai contoh Ethernet menggunakan MTU sebesar 1500 bytes dan FDDI sebesar 4500 bytes. Pada IPv4, fragmentasi dilakukan oleh semua node yang berinteraksi dengan paket. Sedangkan pada IPv6 dilakukan hanya pada end sistem.

\subsection{Mekanisme Transisi IPv4 dengan IPv6}

Secara umum, mekanisme transisi IPv6 dengan IPv4 dapat dilakukan dalam beberapa metode, yaitu: Tunneling, NAT-PT, dan DSTM. 


\section{a. Tunneling}

menggunakan IPv4 sebagai media penghubung antar jaringan IPv6. Paket IPv6 dibungkus dengan paket IPv4, sehingga paket IPv6 pada jaringan IPv4 diperlakukan sebagai payload biasa. Pada end point, header IPv4 dibuka, sehingga yang diperoleh adalah paket IPv6.

b. NAT-PT (Network Address Translation Protocol Translation),

menerjemahkan protokol IPv4 ke IPv6, dan sebaliknya.

\section{c. DSTM (Dual Stack Mechanism Transition)}

merupakan sebuah mekanisme transisi IPv4 dengan IPv6 yang menggunakan dua buah tipe IP pada sebuah node, seperti dijelaskan pada Gambar 3. Dual Stack IP diimplementasikan pada network layer, sehingga pada lapis ini terdapat 2 jenis IP yang berbeda, seperti ditunjukkan oleh Gambar. 4.

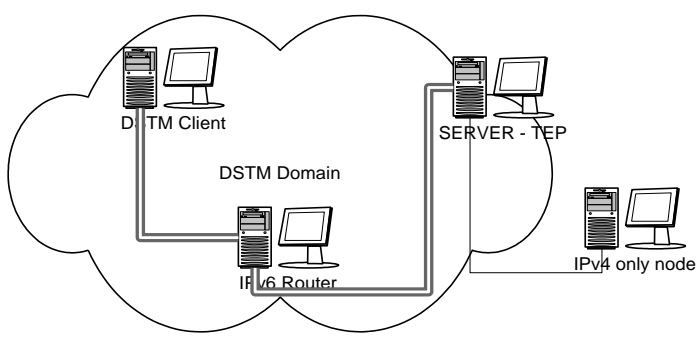

Gambar 3. Arsitektur DSTM

\begin{tabular}{|c|c|}
\hline \multicolumn{2}{|c|}{ Application } \\
\hline \multicolumn{2}{|c|}{ TCP/UDP } \\
\hline IPv4 & IPv6 \\
\hline Network & Interface \\
\hline
\end{tabular}

Gambar 4. Dual IP Stack

\section{Perancangan dan Implementasi DSTM}

DSTM terdiri atas 3 komponen, yaitu

a. DSTM Client

b. DSTM Server

c. DSTM TEP (Tunneling End Point)/Gateway

Setiap node tersebut di atas diimplementasikan pada komputer dengan spesifikasi teknis yang sama :

- Processor $\quad:$ Pentium III - $450 \mathrm{Mhz}$

- RAM : $128 \mathrm{MB}$

- Ethernet Card : 3Com 3c509B Etherlink-10 100Mbps - Operating system : RedHat Linux 7.3. kernel - 2.4.18

DSTM server adalah penyedia alamat IPv4 yang akan diberikan kepada DSTM Client. DSTM Client adalah node tempat implementasi dual IP stack. Tanpa IPv4, DSTM Client tidak dapat berkomunikasi dengan IPv6. DSTM Client juga akan membuat tunnel menuju TEP untuk diteruskan ke jaringan IPv4. TEP merupakan gateway antara jaringan DSTM domain dengan jaringan IPv4 (atau internet). TEP memiliki 2 buah interface yang masing-masing terhubung ke jaringan yang berbeda.

\subsection{Mekanisme Kerja DSTM}

Mula-mula DSTM Client meminta alamat IPv4 pada DSTM Server. Sebagai balasan, DSTM Server akan memberi alamat IPv4 beserta alamat IPv6 dari TEP. Selanjutnya DSTM Client membangun tunnel IPv4 over IPv6 menuju TEP. TEP membuka enkapsulasi IPv6 dan mengirimkan isinya (paket IPv4) menuju jaringan IPv4.

\subsection{Desain Pengukuran Sistem}

Pengujian sistem dilakukan pada tiga jaringan berbeda, yaitu: DSTM, IPv6, dan IPv4, masingmasing konfigurasinya diperlihatkan pada Gambar 5.

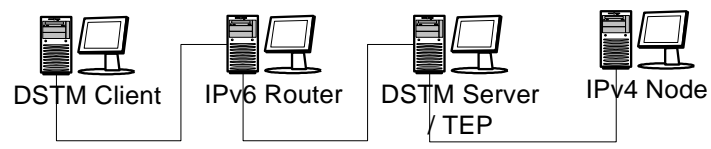

(a) Pengukuran Jaringan DSTM

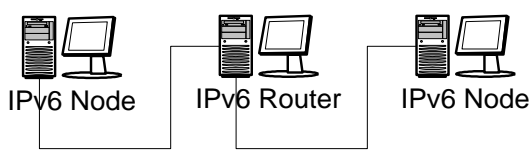

(b) Pengukuran Jaringan IPv6

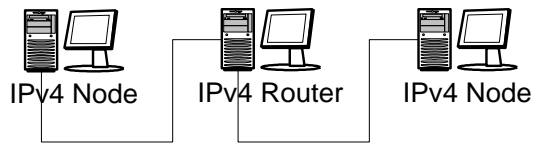

(c) Pengukuran Jaringan IPv4

Gambar 5. Konfigurasi Pengukuran Jaringan

Pengukuran yang`dilakukan pada DSTM Client adalah untuk aplikasi Ping dan FTP. IPv4 node berperan sebagai FTP Server dan IPerf Source. IPv6 Router dan TEP berperan memonitor paket yang melewatinya.

Pengujian dilakukan untuk dua kriteria, yaitu: uji interkoneksi dan pengukuran kinerja (delay dengan MTU berbeda ketika digunakan ICMP, FTP, dan IPerf). Pada masing-masing jaringan dilakukan pengukuran dengan pengiriman 20 paket ICMP untuk 5 ukuran paket berbeda, dan pengiriman file menggunakan FTP dengan 10 ukuran paket berbeda yang dilakukan sebanyak 10 kali.

\section{Hasil dan Analisa}

\subsection{Pengujian Interkoneksi}

\subsubsection{Pengujian Pemberian Address IPv4}

Setelah pengaktifan DSTM Client dengan meminta alamat IPv4 temporal kepada DSTM Server, maka sebuah alamat IPv4 akan digunakan oleh stack pada DSTM Client. Alamat ini aktif jika DSTM Client melakukan hubungan dengan node IPv4. Dalam hal ini digunakan pengujian interkoneksi dengan program aplikasi Ping. Setelah itu IPv4 akan aktif. 
dtil Link encap: UNSPEC

HWaddr 00-00-00-00-00-00-00-00-00-00-00-0000-00-00-00

inet addr:192.168.2.3 P-t-P:192.168.2.1

Mask:255.255.255.255

UP POINTOPOINT RUNNING MTU:1500 Metric:1

RX packets:5 errors:0 dropped:0 overruns:0 frame: 0

TX packets:5 errors:0 dropped:0 overruns:0 carrier:0 collisions:0 txqueuelen:0

$\mathrm{RX}$ bytes: $420(420.0 \mathrm{~b})$

TX bytes: $420(420.0 \mathrm{~b})$

Dari spesifikasi diatas terlihat bahwa dti1 memiliki alamat IPv4 192.168.2.3 yang merupakan alokasi alamat dari DSTM Server sesuai dengan konfigurasi. Hal ini menunjukkan sistem pemberian alamat IPv4 berjalan dengan baik. Sedangkan alamat IPv4 untuk TEP adalah 192.168.2.1.

\subsubsection{Pengujian Pembentukan 4over6 Tunnel}

Tunneling 4over6 pada DSTM dilakukan dengan interface yang disebut DTI (Dynamic Tunneling Interface). DTI ini aktif hanya jika DSTM Client melakukan komunikasi dengan IPv4 host. Dengan perintah iptun6, maka akan terlihat alamat awal dan akhir dari tunnel tersebut .

dtio: ip/ip remote any local any ttl inherit dti1: ip/ip remote 3 fff:ffff:0:f100::2 local 3ffe:ffff:0:f100::2 ttl inherit

\subsubsection{Pengujian interkoneksi IPv4 - DSTM}

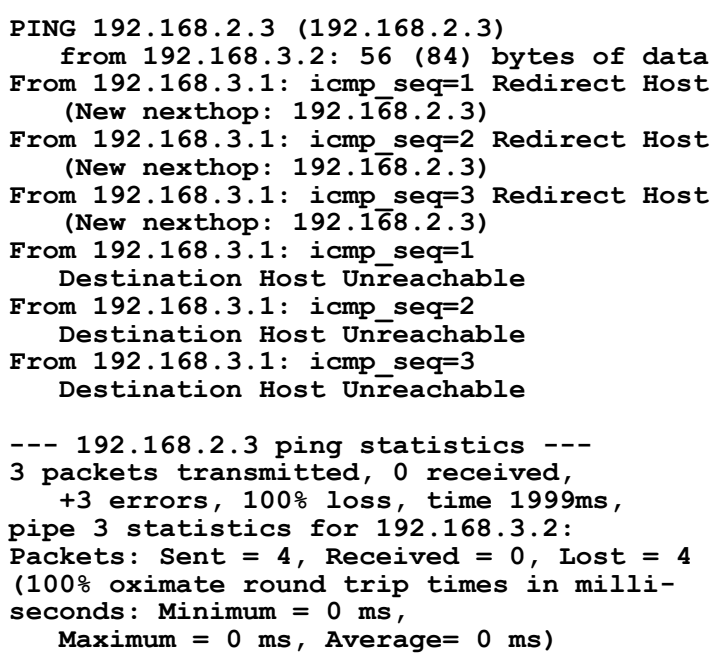

Dari data di atas terlihat bahwa jika hubungan komunikasi diawali oleh IPv4 only host, maka tidak terdapat hubungan dari IPv4 only host menuju DSTM Client. Sehingga DSTM yang diimplementasikan hanya berjalan jika komunikasi diawali dari sisi DSTM Client saja

\subsubsection{Analisa Enkapsulasi paket IPv4 oleh IPv6}

Dalam DSTM domain, paket IPv4 dilewatkan di atas protokol IPv6. Mekanisme ini disebut dengan enkapsulasi. Paket IPv4 dikenal sebagai payload dalam jaringan IPv6, sehingga tidak dikenakan analisis header pada routing dalam jaringan IPv6. Pengamatan proses enkapsulasi dilakukan dengan pengambilan paket melalui penggunaan program cold. Struktur paket dari tiap-tiap pengujian dapat dijelaskan pada Gambar 6.

\begin{tabular}{|c|c|c|c|}
\hline $\begin{array}{c}\text { Mac } \\
\text { Header }\end{array}$ & $\begin{array}{c}\text { IPv6 } \\
\text { Header }\end{array}$ & $\begin{array}{c}\text { IPv6 Next } \\
\text { Frame }\end{array}$ & Data \\
\hline
\end{tabular}

(a) Paket ICMP over IPv6 pada router IPv6

\begin{tabular}{|c|c|c|}
\hline Mac & IPV4 & ICMP \\
Header & Header & paket \\
\hline
\end{tabular}

(b) Paket ICMP pada TEP (setelah dekapsulasi)

\begin{tabular}{|c|c|c|c|}
\hline $\begin{array}{c}\text { Mac } \\
\text { Header }\end{array}$ & $\begin{array}{c}\text { IPV4 } \\
\text { Header }\end{array}$ & $\begin{array}{c}\text { TCP } \\
\text { Header }\end{array}$ & Data \\
\hline
\end{tabular}

(c) Paket FTP pada TEP (Setelah dekapsulasi)

Gambar 6 Struktur Paket Pengujian

Dari pengamatan di atas terlihat bahwa paket yang keluar dari TEP adalah paket IPv4, sedangkan paket yang masuk ke TEP adalah IPv6. Jadi dapat disimpulkan bahwa telah terjadi proses enkapsulasi paket IPv4 over IPv6 dan dekapsulasi paket IPv4 over IPv6, sehingga paket IPv4 dapat dikirimkan melalui jaringan IPv6 yang ada.

\subsection{Pengukuran Kinerja}

\subsubsection{Kinerja Menggunakan ICMP}

Hasil Pengukuran sistem menggunakan paket ICMP diperoleh dari pengiriman paket ICMP untuk 5 ukuran paket berbeda, masing-masing diuji sebanyak 20 kali, sebagaimana diperlihatkan pada Gambar 7. Terlihat bahwa bertambahnya ukuran paket menyebabkan waktu kirim juga semakin lama. Hal ini disebabkan oleh bertambahnya waktu transmisi untuk paket yang berukuran besar ditambah dengan waktu untuk retransmisi.

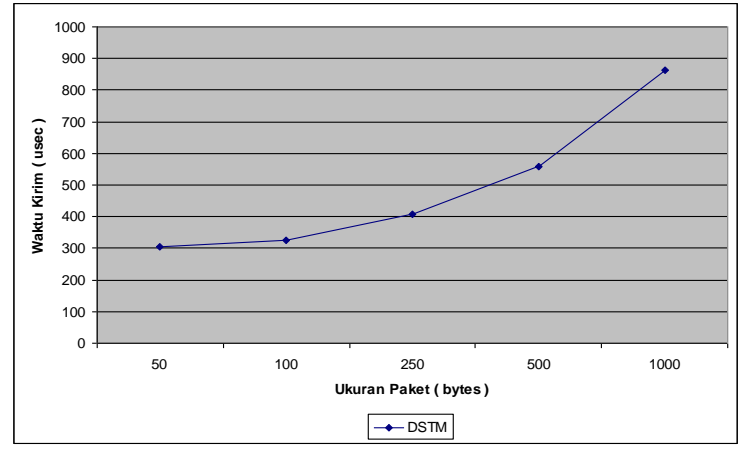

Gambar 7. Hasil Pengukuran ICMP

\subsubsection{Kinerja Menggunakan FTP}

Hasil pengukuran kinerja menggunakan FTP dengan mengambil paket dari IPv4 only node sebagai FTP Server ke DSTM Client ditunjukkan pada Gambar 8. Terlihat bahwa bertambahnya waktu transfer tidak linier dengan bertambahnya ukuran data. Hal ini disebabkan oleh karakteristik protokol 
TCP yang banyak mengontrol aliran paket untuk menghindari adanya kemacetan (congestion). Selain itu, TCP juga berkemampuan untuk mengontrol dan mengirim kembali paket yang rusak. Jumlah paket yang besar akan membutuhkan waktu lebih banyak untuk menjalankan fungsi-fungsi tersebut.

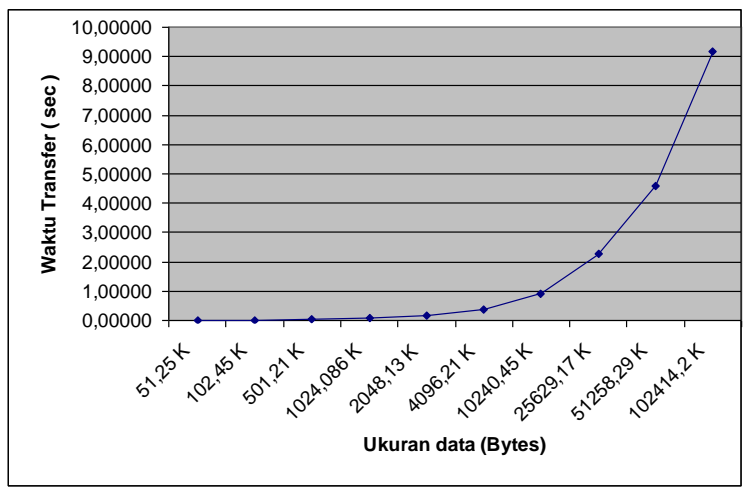

Gambar 8. Hasil pengukuran menggunakan FTP

\subsubsection{Kinerja Menggunakan Iperf}

Pengukuran menggunakan Iperf dilakukan dengan menggunakan proses TCP pada pengiriman paket dan dengan port 80 (HTTP), hasilnya dapat dilihat pada Gambar 9. Untuk setiap penambahan banyaknya paket yang dikimkan, akan terjadi penambahan waktu kirim secara eksponensial, serupa dengan grafik untuk FTP.

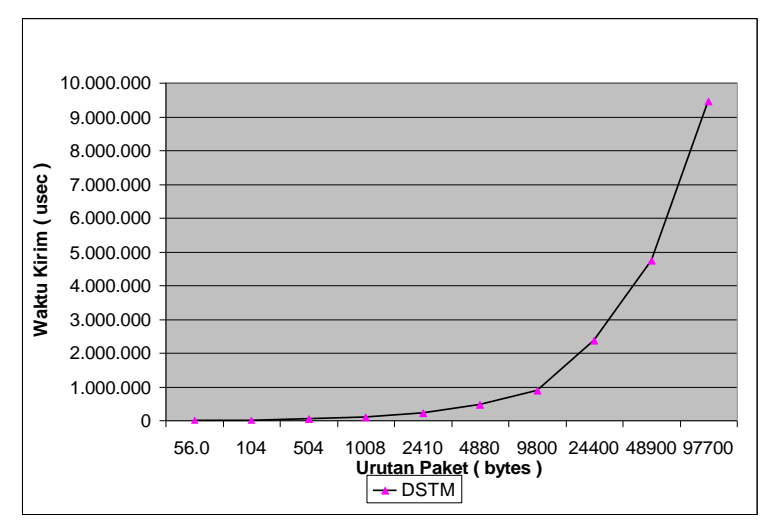

Gambar 9. Hasil Pengukuran Iperf

\subsection{Perbandingan DSTM, IPv4, dan IPv6}

Implementasi DSTM yang melewatkan IPv4 pada IPv6 serta proses enkapsulasi-dekapsulasi akan menyebabkan perubahan kinerja pada jaringan. Pada penelitian ini akan dievalusasi sejauh mana pengaruh perubahan tersebut

\subsubsection{Analisa Kinerja Menggunakan ICMP}

Hasil perbandingan kinerja antara IPv4, IPv6 dan DSTM dari pengukuran menggunakan ICMP diperlihatkan oleh Gambar 10. Hasil perhitungan untuk perbandingan waktu kirimnya ditunjukkan pada Tabel 1.

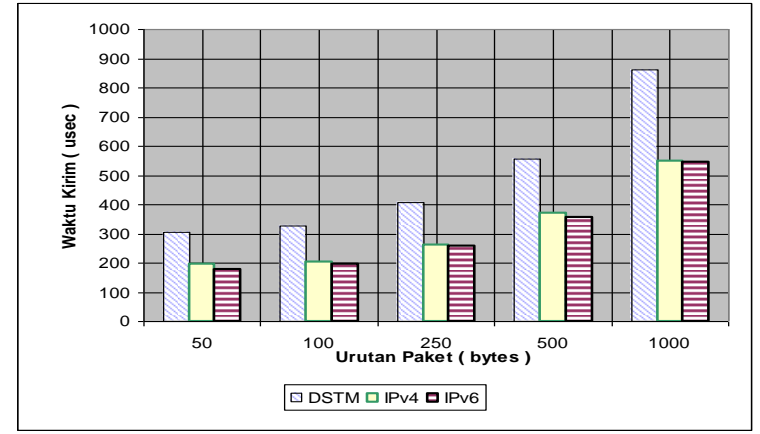

Gambar 10. Perbandingan Waktu Tempuh Paket Melalui DSTM, IPv6 dan IPv4 Menggunakan ICMP

Pada Tabel 1 terlihat bahwa untuk panjang paket yang sama, aplikasi ICMP pada DSTM membutuhkan waktu rata-rata 1,617 kali lebih lama dibandingkan pada IPv6 dan 1,562 kali lebih lama dibandingkan pada IPv4. Aplikasi DSTM pada IPv4 1,035 kali lebih lama dibandingkan pada IPv6.

Tabel 1. Perbandingan Waktu Kirim Paket DSTM Menggunakan ICMP

\begin{tabular}{|c|c|c|c|}
\hline \multirow{2}{*}{$\begin{array}{c}\text { Panjang } \\
\text { Paket } \\
\text { (Bytes) }\end{array}$} & $\begin{array}{c}\text { Perbandingan Waktu Kirim Paket DSTM } \\
\text { Menggunakan ICMP }\end{array}$ \\
\cline { 2 - 4 } & $\begin{array}{c}\text { DSTM } \\
\text { terhadap IPv6 }\end{array}$ & $\begin{array}{c}\text { DSTM } \\
\text { terhadap IPv4 }\end{array}$ & $\begin{array}{c}\text { IPV4 } \\
\text { terhadap IPv6 }\end{array}$ \\
\hline 50 & $1,699: 1$ & $1,567: 1$ & $1,084: 1$ \\
\hline 100 & $1,660: 1$ & $1,615: 1$ & $1,028: 1$ \\
\hline 250 & $1,571: 1$ & $1,554: 1$ & $1,011: 1$ \\
\hline 500 & $1,571: 1$ & $1,507: 1$ & $1,042: 1$ \\
\hline 1000 & $1,585: 1$ & $1,568: 1$ & $1,011: 1$ \\
\hline Rata-rata & $\mathbf{1 , 6 1 7}: \mathbf{1}$ & $\mathbf{1 , 5 6 2}: \mathbf{1}$ & $\mathbf{1 , 0 3 5}: \mathbf{1}$ \\
\hline
\end{tabular}

\subsubsection{Kinerja Menggunakan FTP}

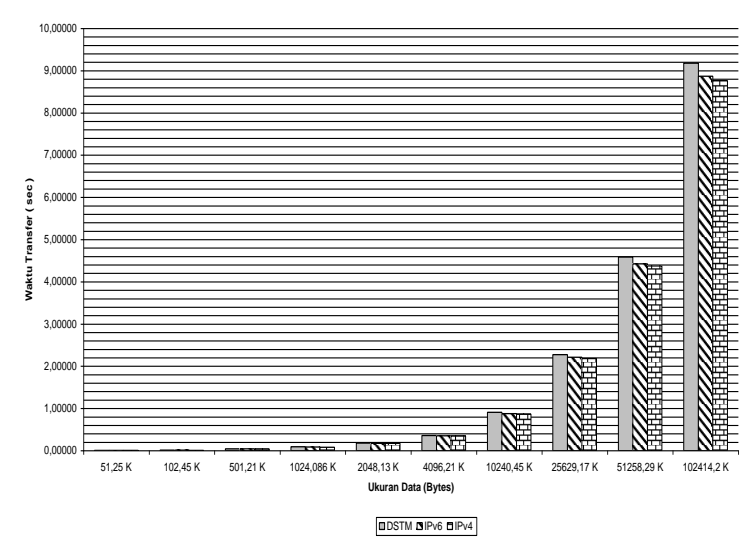

Gambar 11. Perbandingan Waktu Tempuh Paket Melalui DSTM, IPv6 dan IPv4 Menggunakan FTP

Pengiriman data melalui ethernet ke jaringan dibatasi oleh besaran MTU. Data dibagi menjadi paket-paket yang besarnya tergantung dari MTU ethernet itu sendiri. Karena jaringan yang dipergunakan sama, maka besar MTU untuk setiap data yang melewati jaringan IPv6, IPv4, dan DSTM akan sama. Namun header untuk masing-masing jaringan akan berbeda, karena adanya proses enkapsulasi, sehingga beban aktual (actual payload) setiap paket menjadi berbeda-beda. 
Tabel 2. Perbandingan Waktu Kirim Paket DSTM Menggunakan FTP

\begin{tabular}{|r|c|c|c|}
\hline \multirow{2}{*}{$\begin{array}{c}\text { Panjang } \\
\text { Paket } \\
\text { (kBytes) }\end{array}$} & $\begin{array}{c}\text { Perbandingan Waktu Kirim Paket DSTM } \\
\text { Menggunakan FTP }\end{array}$ \\
\cline { 2 - 4 } & $\begin{array}{c}\text { DSTM } \\
\text { terhadap IPv6 }\end{array}$ & $\begin{array}{c}\text { DSTM } \\
\text { terhadap IPv4 }\end{array}$ & $\begin{array}{c}\text { IPV6 } \\
\text { terhadap IPv4 }\end{array}$ \\
\hline 51,25 & $1,179: 1$ & $1,215: 1$ & $1,031: 1$ \\
\hline 102,45 & $1,062: 1$ & $1,080: 1$ & $1,017: 1$ \\
\hline 501,21 & $1,037: 1$ & $1,053: 1$ & $1,015: 1$ \\
\hline 1024,09 & $1,041: 1$ & $1,101: 1$ & $1,058: 1$ \\
\hline 2048,13 & $1,032: 1$ & $1,048: 1$ & $1,015: 1$ \\
\hline 4096,21 & $1,030: 1$ & $1,045: 1$ & $1,014: 1$ \\
\hline 10240,45 & $1,030: 1$ & $1,048: 1$ & $1,017: 1$ \\
\hline 25629,17 & $1,029: 1$ & $1.042: 1$ & $1,013: 1$ \\
\hline 51258,29 & $1,036: 1$ & $1,048: 1$ & $1,011: 1$ \\
\hline 102414,20 & $1,035: 1$ & $1,047: 1$ & $1,012: 1$ \\
\hline Rata-rata & $\mathbf{1 , 0 5 1 : 1}$ & $\mathbf{1 , 0 7 3}: \mathbf{1}$ & $\mathbf{1 , 0 2 0}: \mathbf{1}$ \\
\hline
\end{tabular}

Tabel 2 yang diturunkan dari Gambar 11 menunjukkan bahwa untuk panjang paket aplikasi FTP yang sama, pada DSTM dibutuhkan waktu ratarata 1.051 kali lebih lama dibandingkan pada jaringan IPv6, dan 1.073 kali lebih lama pada IPv4. Aplikasi FTP pada jaringan IPv6 membutuhkan waktu rata-rata 1.020 kali lebih lama dibandingkan pada jaringan IPv4.

\subsubsection{Kinerja Menggunakan Iperf}

Pada penelitian ini, Iperf diset untuk membangkitkan trafik dari pengiriman paket melalui port 80 (HTTP) dengan mekanisme TCP.

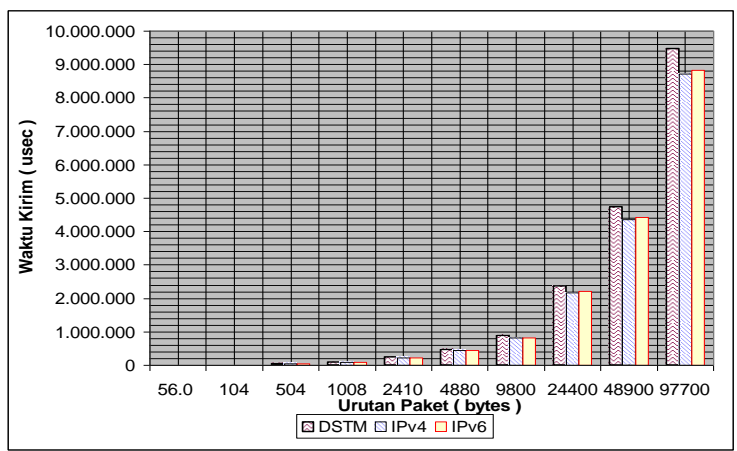

Gambar 13. Perbandingan Waktu Kirim Paket Menggunakan Iperf pada Port 80

Tabel 3. Perbandingan Waktu Kirim Paket DSTM Menggunakan Iperf

\begin{tabular}{|r|c|c|c|}
\hline \multirow{2}{*}{$\begin{array}{c}\text { Panjang } \\
\text { Paket } \\
\text { (kBytes) }\end{array}$} & $\begin{array}{c}\text { Perbandingan Waktu Kirim Paket DSTM } \\
\text { Menggunakan Iperf }\end{array}$ \\
\cline { 2 - 4 } & $\begin{array}{c}\text { DSTM } \\
\text { terhadap IPv6 }\end{array}$ & $\begin{array}{c}\text { DSTM } \\
\text { terhadap IPv4 }\end{array}$ & $\begin{array}{c}\text { IPV6 } \\
\text { terhadap IPv4 }\end{array}$ \\
\hline 51,25 & $1,098: 1$ & $1,182: 1$ & $1,077: 1$ \\
\hline 102,45 & $1,079: 1$ & $1,130: 1$ & $1,047: 1$ \\
\hline 501,21 & $1,074: 1$ & $1,095: 1$ & $1,019: 1$ \\
\hline 1024,09 & $1,073: 1$ & $1,090: 1$ & $1,016: 1$ \\
\hline 2048,13 & $1,074: 1$ & $1,085: 1$ & $1,010: 1$ \\
\hline 4096,21 & $1,072: 1$ & $1,088: 1$ & $1,014: 1$ \\
\hline 10240,45 & $1,072: 1$ & $1,087: 1$ & $1,014: 1$ \\
\hline 25629,17 & $1,073: 1$ & $1,088: 1$ & $1,014: 1$ \\
\hline 51258,29 & $1,072: 1$ & $1,087: 1$ & $1,014: 1$ \\
\hline 102414,20 & $1,072: 1$ & $1,087: 1$ & $1,014: 1$ \\
\hline Rata-rata & $\mathbf{1 , 0 7 6}: \mathbf{1}$ & $\mathbf{1 , 1 0 3}: \mathbf{1}$ & $\mathbf{1 , 0 2 5}: \mathbf{1}$ \\
\hline
\end{tabular}

Pada Tabel 7 yang diturunkan dari Gambar 13, terlihat bahwa untuk panjang paket yang sama, aplikasi IPerf pada jaringan DSTM membutuhkan waktu rata-rata 1,076 kali lebih lama dibandingkan pada jaringan IPv6. dan 1,103 kali lebih lama pada jaringan IPv4. Aplikasi IPerf pada jaringan IPv6 membutuhkan waktu rata-rata 1,025 kali lebih lama dibandingkan pada jaringan IPv4.

\section{Kesimpulan dan saran}

\subsection{Kesimpulan}

1. Untuk aplikasi ICMP, FTP maupun Iperf, jaringan DSTM memiliki kinerja lebih rendah dari pada jaringan IPv6 dan IPv4, karena waktu kirim paket yang dibutuhkan lebih lama.

2. Untuk aplikasi ICMP, waktu kirim paket pada jaringan IPv6 lebih cepat dari pada IPv4. Tetapi untuk aplikasi FTP dan Iperf, waktu kirim paket pada IPv6 lebih lama dari pada IPv4.

\subsection{Saran}

1. Untuk aplikasi yang membutuhkan jaringan dengan kinerja yang baik, sebaiknya tidak menggunakan DSTM sebagai mekanisme transisi dari IPv4 ke IPv6.

2. Untuk mengatasi ketidakmampuan komunikasi yang diawali oleh IPv4 only host, dapat dipakai DNS Server yang akan menterjemahkan request alamat untuk DSTM Client pada jaringan IPv4.

\section{Daftar Pustaka :}

[1] Azcorra, Arturo., The IPv64: IPv4/IPv6 Transition Transition Mechanis, University Carlos III de Madrid, December 2001

[2] Cahyadi, Aris., 2002, Analisa dan Implementasi IPv6 Tunnel Broker Untuk Interkoneksi antara IPv4 dan IPv6, STT Telkom, Bandung.

[3] Che, Rohani Ishak., 2001, IPv6 Turorial,Apricot, Kuala lumpur.

[4] Ettikan Kandasamy Karuppiah, IPv6 Dual Stack Transition Technique Performance Analysis: KAME on FreeBSD as the Case, Cyberjaya, Selangor, Malaysia.

[5] Hensarling, Ken, Testing IPv6 For Prime Time IPv6 Summit. Beijing, China, May 11, 2002.

[6] Karuppiah, Ettikan Kandasamy, Application Performance Analysis in Transition Mechanism from IPv4 to IPv6, Cyberjaya, Malaysia.

[7] NGTRANS Working Group, 2002, Dual Stack Transition Mechanism (DSTM). IETF

[8] RFC 2983, 2000, Transition Mechanisms for IPv6 Hosts and Routers, Internet Society.

[9] Seung Min-Lee, 2001, Dual Stack Transition Mechanism, Kwangwoon University. 